\title{
TERASING DALAM BUDAYA BARAT DAN TIMUR: POTRET "NYAl" HINDIA BELANDA, ABAD XVII-XX
}

\author{
FX. Domini BB. Hera \\ Jurusan Sejarah, Universitas Negeri Malang \\ francis_x_hera@yahoo.co.id \\ Daya Negri Wijaya \\ MA History, University of Sunderland, UK \\ Dayawijaya15@yahoo.com
}

\begin{abstract}
"Nyai" is the concept that refer to native woman (including Chinese and Japanese woman) who life without married relationship with European, Chinese, or Arabian man. However the position of "Nyai" is not accepted by foreigner (commonly western society) and indigenous people (commonly eastern society), but they have important role in the family and social-culture in Hindia Belanda, XVII-XX. Beside the negative image attaching to "Nyai", they also have positive side in society life as cultural mediator between western and eastern culture. It is giving a chance for "Nyai" to give any cultural influence from one society or group to another. The study can give the reader a lot of understanding about development of sexuality in Nusantara (The past Indonesia) and the point is the study like the basic form to explain the phenomena of unmarried couple today. In short, this study will focus on the image and role of "Nyai" in Hindia Belanda, XVII-XX.
\end{abstract}

Keywords: Nyai, Alienation, Hindia Belanda

\section{A. Pendahuluan}

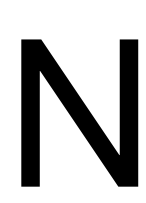

yai adalah julukan bagi seorang wanita pribumi, kadangkala juga bagi wanita Cina atau Jepang, yang hidup bersama pria Eropa, Cina atau Arab (Berg, 2010) tanpa hubungan pernikahan. Walaupun tidak mempunyai kedudukan resmi sebagai ibu rumah tangga, seorang Nyai umumnya memegang peranan ibu rumah tangga di rumah sang pria. Sudah di zaman VOC (Vereenigde Oost-Indische Compagnie) atau Persekutuan Dagang Hindia-Timur sejumlah lelaki hidup bersama dengan seorang Nyai tanpa pernah menikahinya secara resmi, pun jika sang Nyai telah melahirkan anak dari lelaki tersebut.

Di periode VOC, sejak tahun 1652 hanya para petinggi dan pedagang VOC terpenting yang diperbolehkan datang ke Hindia Belanda bersama istri (Taylor, 2009: 186). Sebelum diadakannya peraturan pembatasan tersebut, VOC justru melancarkan kedatangan para wanita dari Belanda. Selain istri para petinggi VOC, juga kelompok-kelompok kecil gadis Belanda didatangkan ke Hindia Belanda untuk menetap dan menikah dengan pejabat-pejabat VOC berpangkat tinggi maupun rendah. Semisal para gadis dari rumah-rumah yatim piatu di Belanda. Hal ini merupakan suatu kebijakan pemerintah VOC untuk mengurangi kecenderungan pada pria Belanda hidup bersama Nyai, yang pada saat itu tidak sesuai dengan peradaban tinggi bangsa Belanda (Hellwig, 2007). Pada tahun 1647 terdengar suarasuara yang yang tidak menghendaki kedatangan wanita dari Belanda, dengan pemberian alasan bahwa wanita Belanda meningkatkan pengeluaran pemerintah. Di samping itu dikatakan juga bahwa dengan dorongan para istri, pejabat-pejabat VOC lebih mementingkan dirinya dan cenderung membuka perdagangan pribadi dengan merugikan VOC. Akhirnya pada tahun 1657 ditetapkan bahwa hanya istri para petinggi dan pedagang VOC tertinggi yang diizinkan datang ke Hindia Belanda. 
Di kalangan pegawai perkebunan Belanda atau Eropa sampai tahun 1922 masih berlaku larangan untuk menikah dengan wanita Eropa. Peraturan tersebut berdasarkan perhitungan bahwa pegawai muda dan bujangan memerlukan gaji yang lebih rendah dibandingkan seorang pegawai yang berkeluarga. Disamping itu, diperkirakan juga bahwa sebuah pernikahan dengan wanita Eropa dapat menghambat hubungan antar pegawai perkebunan dan penduduk pribumi. Maka dengan sendirinya jalinan hubungan antara pria Eropa dan wanita-wanita pribumi tetap berlangsung. Sejumlah besar pria Belanda dan wanita pribumi hidup dalam pernikahan resmi. Namun, praktek pernyaian, di mana wanita pribumi menempati kehidupan kedudukan sebagai pengurus rumah tangga sekaligus sebagai pengganti istri sang laki-laki yang juga majikannya, tetap umum dan bahkan dikehendaki oleh para pengusaha perkebunan bagi pegawai-pegawai muda mereka (Blusse, 2004).Namun, banyak juga pria yang tetap memilih hidup tanpa pernikahan resmi dengan seorang Nyai dan tidak menikahi seorang wanita dari negaranya sendiri. Alasannya secara keuangan seorang Nyai tidak banyak memberi beban, sebab terbiasa hidup sederhana, sedangkan wanita Eropa terbiasa dengan tingkat kehidupan yang tinggi (Darmarastri, 2002: 1-24 dan Baay, 2010). Tulisan ini akan berfokus pada bagaimana citra dan peran nyai dalam pengembangan budaya kolonial.

\section{B. Keberadaan Nyai pada Masa Kolonial Abad XVII-XX}

stilah Nyai di Indonesia merupakan istilah yang populer. Nyai sendiri memiliki beragam sebutan baik dalam legenda, mitos, dan tokoh rekaan. Ada Nyai Ronggeng Dukuh Paruk karya Novelis Ahmad Tohari. Nyai juga berarti istri (nyonya) pengasuh pondok pesantren dari Kyai (gelar ulama di Jawa), misalnya Nyai Ahmad Dahlan. Sedangkan Nyai di Kalimantan berarti gelar untuk wanita terhormat yang bukan keturunan bangsawan, misalnya Nyai Undang, Nyai Siti Diang Lawai, Nyai Ratu Komalasari. Ratu Komalasari adalah permaisuri Sultan Adam dari Kesultanan Banjar, penambahan gelar Nyai di depan gelar 'Ratu' menunjukan bahwa dia bukan berasal dari kalangan bangsawan. Nyai adalah sebutan umum di Jawa Barat, khususnya bagi wanita dewasa.

Dalam tulisan ini aspek yang dibahas ialah Nyai sebagai wanita pendamping pria Eropa, maupun bangsa asing lainnya, yang dikenal secara luas sebagai gundik. Adapun gundik atau mistress diartikan sebagai: (1) istri tidak resmi; selir; (2) perempuan piaraan (bini gelap).. Namun, kata ini memiliki konotasi yang lain pada zaman kolonial di Hindia Belanda. Ketika itu, Nyai berarti 'gundik, selir, atau wanita piaraan para pejabat dan serdadu Belanda'. Nyai bersinonim dengan gundik dan selir. Baik nyai, gundik, maupun selir, dalam Kamus Besar Bahasa Indonesia (KBBI), diartikan sebagai "bini gelap", perempuan piaraan, dan istri yang tidak pernah dikawini secara resmi.

Keberadaan masyarakat "Eropa" di Hindia Belanda terjadi dalam pola-pola yang rumit sebagai akibat reproduksi antar ras selama berabad-abad dan tradisi pergundikan yang telah berakar kuat. Banyak perempuan pribumi bekerja sebagai nyai, memasak dan mengurus rumah tangga orang Belanda yang belum menikah, sekaligus sebagai pelayan seksual. Praktik itu, sesungguhnya, didorong dan boleh disebut bahkan dilembagakan oleh adanya kebijakan VOC (Verenigde Oost-Indische Compagnie) pada 1652 yang membatasi imigrasi perempuan Belanda, dan menuntut berbagai persyaratan rumit kepada perkawinan resmi antara laki-laki Belanda dan perempuan Jawa.

Kebiasaan hidup bersama gundik masih banyak dilakukan sampai pada pergantian abad. Meskipun benar praktik itu tidak terlalu meluas di Jawa, tetapi tradisi ini masih merajalela di pantai timur Sumatera, Deli misalnya. Sejumlah perempuan dari Jepang juga bekerja sebagai gundik di Deli; dan karenanya, kisah rakyat bahwa Nyai itu layaknya "kamus berjalan" atau melayani pria Belanda totok sebagai guru privat adat Indonesia pada kenyataannya hanyalah imajinasi kolonial. Bagaimanapun, di pantai timur Sumatera, sudah merupakan keseharian yang normal bahwa pekebun karet atau tembakau asal Eropa memilih seorang perempuan Jawa cantik dari kalangan buruh kontrak yang bari tiba, baik yang sudah menikah atau belum, dan 
mewajibkan perempuan itu tinggal serumah dan melayaninya di tempat tidur.

Setelah berapa lama, sebagian kesepakatan ini akan menghasilkan satu atau beberapa anak yang berkulit kuning gading. Seorang Nyai mungkin menganggap dirinya sedikit-banyak memiliki hak istimewa, meskipun pada kenyataannya para kuli memandangnya tidak suci, tercemar oleh hubungannya dengan orang kulit putih "kafir", pemakan babi dan peminum jenever.

\section{Kesenjangan Antara Nyai dan Buruh Wanita}

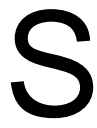
ebagian besar kuli laki-laki harus bekerja di lumpur tempat ular bersarang sambil menyiangi jajaran panjang tanaman tembakau selama musim hujan. Buruh perempuan juga harus bekerja sangat keras ketika berburu ulat di perkebunan tembakau di bawah terik matahari, memilah daun tembakau, atau menyadap karet di perkebunan milik orang Eropa. Sebaliknya, perempuan yang dipilih menjadi Nyai menghabiskan hari kerja yang sama panjangnya dengan mengurus rumah tangga, mengawasi kerja para pembantu rumah tangga, dan melayani hasrat dan nafsu majikan mereka. Nyai hidup dalam keseharian yang penuh kerja berat, nafsu seksual murahan, dan penghinaan lainnya (Gouda, 2007: 196-204). Walaupun demikian, bekerja sebagai gundik jauh berbeda dari pekerjaan menyunggi segunung daun tembakau di atas kepala, memikul ember berat berisi getah karet, atau tinggal di pondok kumuh, yang penuh sesak dengan kuli Cina atau Jawa yang saling bermusuhan dan suka berjudi.

Tidak berbeda jauh kalangan militer juga tergiur untuk memakai nyai dalam memuaskan nafsunya. Hal ini dapat terjadi karena kebanyakan dari mereka tinggal serumah bersama pembantu rumah tangga pribumi, anggota Angkatan Darat Kerajaan di Hindia Belanda (KNIL, Koninklijk Nederland Indische Lagere) di seluruh Nusantara. Pendapat publik Belanda di metropolis Eropa telah membentuk suatu bayangan penuh skandal tentang barak militer di Hindia sebagai tempat yang penuh maksiat. Bahkan dalam sebuah ruangan besar ratusan prajurit tidur bersama gadis atau pembantu rumah tangga mereka di tempat tidur, yang bahkan tidak bisa dipisahkan oleh tirai satu dengan yang lainnya. Tanpa mengindahkan kesopanan mereka bercinta di hadapan penghuni lainnya. Secara sarkastik tidak ubahnya seperti binatang yang tak mengenal malu. Meskipun demikian, praktik tersebut hendaknya tidak disamakan dengan pelacuran profesional. Dalam Encyclopaedie van Nederlandsch-Indie tahun 1919 dinyatakan bahwa Nyai yang tinggal di barak juga memiliki konsepsi tersendiri mengenai cinta. Bagaimanapun, selama masalah pelacuran di Hindia tidak ditangani secara tegas, maka dilihat dari segi manfaat, pergundikan di barak tetap merupakan suatu kebutuhan.

\section{Pembauran Ras dan Nyai}

$\sigma^{\text {t }}$ tereotip Nyai berasal dari pribumi dan pribumi identik dengan kemelaratan telah menjadi momok rasialis yang berkembang di Hindia Belanda. Istilah kemelaratan menjadi lebih jelas terkait dengan kemelut seksual keturunan Eurasia dibandingkan dengan ancaman revolusi kaum proletar. Kemelaratan menimbulkan kecemasan menyangkut reproduksi antarras lebih lanjut, "kebiadaban" seks, mengaburkan pemilahan sosial yang terjadi, jika dibandingkan ancaman pemberontakan anti kapitalis. Namun tidak menutup kemungkinan adanya pandangan positif tentang perkawinan campur. Pandangan positif ini didasarkan pada kecemasan bahwa ras Barat yang ditransplantasikan ke dalam kehangatan tropis yang menggiurkan untuk dikutuk dan akan berakhir dalam kesia-siaan. Kecuali jika orang-orang Eropa menghimpun kembali gen mereka melalui prokreasi dengan pasangan setempat.

Rangkaian argumentasi di atas, baik dalam jurnal ilmiah maupun sastra populer dikaitkan dengan logika evolusioner neo-Lamarckian dan terutama dengan gagasan Gregor Mendel tentang hibriditas dan mutasi spesies progresif. Bagaimanapun, diskusi biologi tentang pembauran ras sebagai sarana bertahan hidup bagi orang-orang Eropa berkulit putih di abad ke-20 dalam lingkungan khatulistiwa yang panas terik untuk memberi jalan pada tekanan pemisahan yang amat ketat antar kelompok etnis. Karenanya, ketakutan terhadap gadis-gadis Indo, khususnya 
keturunan Nyai, yang melarat. Pada periode abad ke-20 itulah, kepekaan sosial masyarakat totok lebih menonjol. Dalam imajinasi publik orang Eropa, orang-orang Indo dilinat sebagai bukti nyata "kebiadaban" seksual dan kurangnya disiplin diri dalam praktik kolonial Belanda kala itu.

Gadis-gadis Indo bernasib malang jika dibandingkan dengan para lelaki Indo. Para lelaki Eropa jika mau mengakui anak lelakinya yang Indo maka si anak tersebut akan diakui statusnya sama seperti stratifikasi Eropa (Iswara, 98-105). Sebaliknya, anak-anak perempuan berdarah campuran merupakan personifikasi jurang perbedaan budaya yang sangat lebar dan dalam antara nilai-nilai Eropa yang beretos kerja keras dan beretika. Namun banyak penduduk kolonial yang menyalahkan para ibu pribumi, seperti Nyai, atas merosotnya martabat putri mereka yang berkulit zaitun. "Perilaku zinah tak bermoral" perempuan pribumi dan "berkarakter rendah" telah mendorong mereka untuk menjadi pembantu rumah tangga sekaligus mitra seks laki-laki Eropa sejak awal, sebagai gundik.

Bahkan para priyayi Jawa pun memiliki pandangan hinaan aristokratis terhadap gadis-gadis Indo, sebab mereka termasuk golongan "sosial rendah" dari ibu mereka. Sikap umum orang Jawa pada awal abad ke-20 memperlihatkan pandangan priyayi yang merendahkan gundik pribumi dan anak-anak mereka yang berdarah campuran itu. Mereka merupakan perempuan yang "rendah dan kotor", para perempuan tak tahu malu, yang telah menentang aturan kesopanan Jawa dan "tanpa budaya sekedar digerakkan oleh nafsu birahi". Para perempuan ini dicap tidak memiliki moral yang kuat, menjual kehormatan mereka demi kehidupan yang mewah, dan menciptakan "keluarga pelacur yang ditakdirkan akan tenggelam dalam kesia-siaan", tanpa meninggalkan jejak dalam catatan resmi sejarah peradaban Jawa.

\section{E. Nyai dan Akulturasi Budaya Kolonial di Hindia Belanda Abad XVII-XX}

$\mathrm{P}$ enduduk kolonial pada abad XVII-XX terdiri dari orang Eropa yang dibagi dalam Eropa Belanda dan Eropa nonBelanda (Jerman, Prancis, Swiss, Inggris,
Scotlandia, Irlandia, Denmark, Vlaming, Polandia), Orang Indo-Eropa, Non-Melayu, Mardijker (golongan masyarakat yang berasal dari budak belian yang sejak abad XVII dibeli orang Belanda di berbagai pusat pelayaran dan perdagangan Portugis di India), Tionghoa, dan suku bangsa pribumi (Makasar, Ambon, Bali Sunda, dan Jawa) (Groeneboer, 1995 dan Suratminto, 2008:13). Maka, secara demografis, Hindia Belanda adalah wilayah jajahan yang multietnik dan multikultural (Taylor, 2009). Dengan adanya kehadiran bangsa Eropa dan asing lainnya di Hindia Belanda, merupakan hal yang wajar apabila kemudian terjadi suatu proses akulturasi budaya dalam kehidupan masyarakat sebagai akibat terjadinya kontak antara orang-orang Eropa tersebut dengan penduduk pribumi yang salah satunya melalui praktek pergundikan. Di dalam hubungan pergundikan yang terjadi antara tuan Eropa dengan Nyai pribumi menyebabkan terjadinya suatu proses akulturasi antara budaya Barat dan Timur baik secara langsung maupun tidak langsung.

Meskipun kehadiran Nyai tidak dapat diterima dengan baik oleh masyarakat Barat dan Timur, namun tanpa disadari secara perlahan telah terjadi tahap-tahap pengenalan, pemahaman, penerimaan, dan bahkan sampai pada pelaksanaan budaya baru yang merupakan hasil percampuran dari dua budaya, yaitu budaya Barat yang dibawa oleh si Tuan Eropa dengan budaya Timur yang berasal dari Nyai pribumi. Melalui para Nyai inilah masyarakat pribumi golongan bawah memperoleh pengetahuan mengenai bahasa, adat istiadat serta nilainilai hidup bangsa Eropa yang kelak dapat disampaikan kepada masyarakat sebangsa.

Hasil akulturasi budaya yang terjadi salah satunya adalah berupa gaya hidup yang tampak dari tata busana yang terdapat pada masyarakat Batavia, sebagai contoh. Cara berpakaian kaum perempuan dari golongan atas Batavia, baik dari kelompok Eropa, Indo maupun pribumi yang diwakili oleh Nyai yakni pada kain yang dikenakan berupa sarung sutera dengan memakai pending dan tidak mengenakan kemben atau selendang penutup dada. Kebaya yang dikenakan dengan sengaja berukuran besar kedombrongan dilengkapi peniti dan memakai sumbang kerabu. Rambut mereka 
disanggul dengan gaya ekor bebek atau ekor udang dengan tusuk konde serta mengenakan remong sutera. Bagi yang kaya akan melengkapi penampilannya dengan mengenakan sepasang selop berhias benang emas atau bermotifkan bunga-bunga.

\section{F. Citra Nyai dalam Dunia Sastra dan Seni}

$\mathrm{H}$ ikayat Siti Mariah (Moekti, 2003) adalah sebuah hikayat dalam arti sesungguhnya, yakni sebuah cerita petualangan yang hebat dari tokoh-tokoh utamanya yang di dalamnya juga terkandung kejadian-kejadian supernatural. Hikayat Siti Mariah ini menceritakan petualangan dan kisah roman di seputar dunia pernyaian atau pergundikan dengan tokoh utamanya, Siti Mariah, di zaman kolonial Hindia Belanda. Hikayat ini banyak mengungkap situasi mengenai dunia pernyai-an di Indonesia pada zaman kolonial. Pernyaian atau pergundikan adalah lembaga perkawinan tanpa pengesahan dari negara maupun agama. Lembaga perkawinan ini terjadi karena pihak pria dalam posisi sosial-ekonomi yang lebih tinggi ketimbang pihak perempuan.

Praktik pergundikan semacam ini lazim terjadi pada masa kolonial. Seorang pria kolonial, atau dalam hal ini penjajah Belanda, sebelum menikah resmi dengan perempuan bangsanya sendiri atau yang sederajat biasanya mengambil seorang atau beberapa gadis pribumi untuk dijadikan gundik atau nyai atau istri tidak resmi. Kendati para nyai itu layaknya hidup sebagai seorang istri dan bahkan mempunyai anak dari pria kolonial, namun ia harus rela meninggalkan kehidupannya sebagai nyai manakala pria kolonial tersebut memutuskan menikah dengan perempuan bangsanya sendiri. Sebagai konsekuensinya ia bahkan harus rela melupakan bahwa ia pernah bersuami dan mempunyai anak yang pernah dilahirkannya.

Diceritakan bahwa Siti Mariah adalah anak di luar perkawinan antara Elout van Hogerveldt, seorang kontrolir tebu, dengan seorang gadis pribumi bernama Sarinem. Ketika lahir, Siti Mariah dinamai Urip. la diberi nama Urip karena pernah jatuh sewaktu lahir, namun bisa tetap hidup atau urip. Urip tidak pernah mengenal ayah kandungnya sendiri karena sewaktu ia masih dalam kandungan, ayah kandungnya, Elout van Hogerveldt, telah meninggal. Urip pernah hampir dibuang ke jurang oleh Wongsodorono, seorang petani bertabiat buruk yang tak lain adalah ayah tirinya sendiri, sewaktu masih berumur sebelas bulan. Sarinem, ibu Urip, dipaksa kawin dengan Wongsodorono oleh ayahnya sewaktu hamil 7 bulan. Namun, Urip masih beruntung tidak jadi dibuang karena Wongsodorono akhirnya menjual Urip kepada Joyopranoto, seorang mandor gula di Sokaraja yang sudah lama berkeluarga namun belum punya anak. Urip kemudian tumbuh menjadi gadis indo yang cantik dengan nama Siti Mariah.

Kisah petualangan dan roman Siti Mariah dimulai ketika ia mulai menjalin cinta dengan seorang opsiner gula bernama Henry Dam. la kemudian dijadikan nyai oleh Dam dan memperoleh anak darinya yang diberi nama Ari. Namun, kebahagiaan Mariah ternyata tidak berlangsung lama. Kehidupan rumah tangganya terusik lantaran pengaruh Nyonya van Holstein, pemilik pabrik gula tempat Dam bekerja. Dengan segala cara, termasuk dengan menggunakan jasa dukun, Nyonya van Holstein memengaruhi Henry Dam untuk menjauhi Siti Mariah sehingga Henry Dam dapat menikahi putrinya Nona Lucie. Usaha tersebut berhasil, Mariah dipaksa keluar dari kehidupan Dam dan ia pun harus berpisah dengan anaknya, Ari. Setelah sempat kabur dari rumah keluarganya, menyamar jadi jongos dan menjadi Nyonya Esobier, Siti Mariah akhirnya dipertemukan kembali dengan Henry Dam dan anaknya, Sinyo Ari, berkat bantuan Sondari. Seperti juga dengan hikayat-hikayat lain, sang tokoh cerita akan memperoleh kemenangan setelah melewati petualangan yang hebat.

Beberapa karya sastra yang menggambarkan Nyai seperti karya legendaris Nyai Dasima oleh G. Francis (dalam Manusama, tt., Sutedja-Liem, 2008: 277-287 dan Ardan, 2007). Di sejumlah karya sastra yang terbit pada masa kolonialisme, seorang Nyai selalu digambarkan sebagai sosok perempuan yang suka selingkuh, bodoh, dan suka mencuri harta tuannya. Cerita Nyai Dasima yang dikarang $\mathrm{G}$. Francis misalnya. Dasima, perempuan dari Kampung Koeripan menjadi 
nyai Tuan Edward W. la sangat dicintai dan dimanjakan layaknya istri yang sah. Namun, Dasima yang rupanya elok ternyata bukan perempuan yang bisa dipercaya. la serong dengan Baba Samioen dari Kampung Pedjambon. Cerita Nyai Dasima di atas memiliki kesamaan dengan cerita Si Tjonat karangan F.D.J. Pangemanann, yang anehnya adalah pengarang pribumi. Adalah Saipa, nyai Tuan Opmeijer, asal Desa Tjirenang yang sangat elok dan muda belia. Sebelum menjadi nyai Tuan Opmeijer, Saipa dijual Kaenoen, abahnya, kepada Tjengkao seharga 40 Gulden dan kemudian dijual lagi seharga dua ratus rupiah. Selama menjadi nyai, Saipa sangat dicintai tuannya. Tetapi, Nyai Saipa berbuat serong dengan si Tjonat, jongos di rumahnya. Bahkan, Saipa memilih kabur bersama si Tjonat setelah terlebih dahulu mencuri uang, perhiasan, dan barang tuannya. Oleh Pramoedya Ananta Toer, cerita tentang seorang nyai diangkat lewat tokoh Nyai Ontosoroh dalam roman Bumi Manusia. Pram menggambarkan, Ontosoroh tidak sekadar nyai yang hanya menjadi objek seksual dan prestise sosial tuan kolonial. Nyai Ontosoroh menghadirkan dirinya tidak lagi sekadar gundik, piaraan, dan pajangan tuannya. Begitu pun tabiat suka serong yang dilekatkan pada nyai dibantah Ontosoroh, ia tidak genit saat menerima tamu lelaki. Ontosoroh menjelmakan dirinya menjadi sosok nyai yang berbeda. la merupakan harmonisasi dari paras dan rupa Timur yang elok dengan keuletan, keberanian, dan kepintaran seorang perempuan Eropa. Di titik inilah Ontosoroh menjelmakan dirinya sebagai bagian dari politik narasi kebangsaan. la hadir, mengiringi sekaligus mengambil bagian di dalam pergulatan kebangsaan sepanjang awal sampai pertengahan abad ke-19, masa awal kebangkitan nasional.

Cerita tentang seorang Nyai diangkat juga dalam Cerita Nyai Sarikem (1900), Nyai Isah (1903), Nyai Permana (1912), Nyai Mirdja (Kleian, 1938) dan Mirah dari Banda (Rambe, 2010). Film dan opera menjadi wahana baru pencitraan Nyai di masa kolonial Belanda. Film Nyai Dasima diproduksi pada tahun 1928. Adapun opera seperti Komedi Stamboel turut mementaskan Nyai di panggung dengan iringan musik dan langgam Melayu.
Pada kaum pria dapat dilihat dari gaya busana para pria Belanda atau Eropa yang menjadi senang mengenakan sarung dan baju serta celana piyama yang bermotif batik. Jenis-jenis pakaian itu hanya mereka kenakan pada saat bersantai di rumah sedangkan pakaian yang dikenakan untuk menghadiri acara-acara resmi tetaplah pakaian-pakaian Eropa. Di samping itu, pada masa pemerintahan VOC juga muncul kegemaran memakan sirih di kalangan perempuan Indo, namun Lady Olivia Marianne Raffles pada periode 1806-1811 tidak menyukainya dan berusaha keras dengan segala cara untuk menghapus kebiasaan tersebut seperti juga keinginannya untuk menghapus kebiasaan berpakaian sarung dan kebaya di kalangan istri-istri pejabat kolonial, namun usahanya itu tidak berhasil (Stockdale, 2010). Kegemaran untuk berpakian sarung dan kebaya masih tetap lestari oleh para wanita Eropa dan Indo sampai dengan Pemerintah Hindia Belanda berlangsung.

\section{G. Penutup}

$\begin{array}{lcc}\text { ergundikan } & \text { sudah } & \text { ada sejak } \\ \text { perdagangan } & \text { mulai } & \text { marak di } \\ \text { Nusantara, } & \text { namun } & \text { semakin }\end{array}$ bertambah jumlahnya ketika masa VOC. Adanya peraturan yang dikeluarkan VOC yang mengharuskan tentara maupun pegawainya untuk berstatus bujangan dan larangan dari pihak Gereja Reformasi Protestan terhadap perkawinan campur antara pria Eropa dengan wanita Asia atau dalam hal ini pribumi, menyebabkan praktek pergundikan muncul kembali demi memenuhi kebutuhan seksual-biologis para pria Eropa tersebut. Lelaki Eropa di perantauan seperti Nusantara tidak hanya hidup dengan perempuan-perempuan setempat, tetapi juga menikah dengan perempuan pribumi asli maupun yang berdarah campuran (Indo). Hal ini sebagai suatu kebiasaan akan tradisi yang normal. Masalah perempuan simpanan dalam masyarakat kolonial memang unik. Bangsa kulit putih telah menjalani hidup bersama dengan perempuan-perempuan pribumi hampir di semua masyarakat kolonial, baik di Asia, Afrika, atau Amerika Selatan. Kehidupan kolonial di mana-mana tampaknya akan "digenangi oleh masalah seks". Akan tetapi, di Hindia Belanda, 
pertautan antara ras menjadi bagian dari "moral dan adat kebiasaan di wilayah tersebut adalah laki-laki lajang, baik dari kelas atas maupun kelas bawah" hidup bersama dengan perempuan simpanannya. Meskipun demikian, di balik segala kesan negatif yang disandangnya, Nyai memiliki peran positif dalam kehidupan bermasyarakat yakni sebagai cultural mediator antara budaya Barat dan Timur. Hal ini tentu memberikan kesempatan kepada Nyai untuk memasukkan pengaruh kebudayaan dari suatu kelompok kepada kelompok yang lain. Meskipun pengaruh tersebut tidak secara langsung disadari.

\section{DAFTAR RUJUKAN}

Ardan, S. M. 2007. Nyai Dasima. Depok: Komunitas Bambu.

Baay, R. 2010. Nyai dan Pergundikan di Hindia Belanda, 1870-1928. Terjemahan oleh Siti Hertini Adiwoso. Depok: Komunitas Bambu.

Berg, L. W. C. Van den. 2010. Orang Arab di Nusantara. Terjemahan oleh Rahayu Hidayat. Depok: Komunitas Bambu.

Blusse, L. 2004. Persekutuan Aneh: Pemukim Cina, Wanita Peranakan, dan Belanda di Batavia VOC. Yogyakarta: LKiS.

Darmarastri, H. A. 2002. Keberadaan Nyai di Batavia. Dalam Lembaran Sejarah, Vol. 4, No. 2, 2002, hlm. 1-24.

Gouda, F. 2007. Dutch Culture Overseas: Praktik Kolonial di Hindia Belanda 1900-1942. Terjemahan oleh Jugiarie Soegiarto dan Suma Riella Rusdiarti. Jakarta: Serambi IImu Semesta.

Groeneboer, K. 1995. Jalan ke Barat: Bahasa Belanda di Hindia Belanda 1600-1950, Sejarah Politik Bahasa. Jakarta: Erasmus Educatief.

Hatley, B. 2008. Postkolonialitas dan Perempuan dalam Sastra Indonesia Modern. Dalam Foulcher, K. dan Day, T. (Eds.), Sastra Indoensia Modern: Kritik Postkolonial, Edisi Revisi, Clearing a Space. Terjemahan oleh Koesalah Soebagyo Toer dan Monique Soesman.

Hellwig, T. 2007. Citra Kaum Perempuan di Hindia Belanda. Jakarta: Yayasan Obor Indonesia.

Iswara, H (Ed.). 2001. Ketoprak Betawi. Jakarta: PT. Intisari Mediatama.

Kleian, J. 1938. Njai Mirdja. Hoorn: De Steenuil.

Manusama, A. Th. Tanpa tahun. Nyai Dasima: Het Slachtoffer van Bedrog en Misleiding, Een Historische Zedenroman van Batavia. San Francisco \& Den Haag.

Moekti, H. 2003. Hikayat Siti Mariah. Jakarta: Lentera Dipantara.

Rambe, H. 2010. Mirah dari Banda. Jakarta: Yayasan Obor Indonesia.

Stockdale. J. J. 2010. Eksotisme Jawa: Eksotisme Sejarah Pulau Jawa, Ragam Kehidupan dan Kebudayaan Masyarakat Jawa 1768-1806. Terjemahan oleh Anik. Yogyakarta: Progresif Book.

Sutedja-Liem, M. 2008. Menghapus Citra Buruk Njai Dalam Karya-karya Fiksi Berbahasa Melayu (1896-1927). Dalam WACANA, Vol. 10 No. 2, Oktober 2008, hlm. 277286.

Suratminto, L. 2008. Makna Sosio-Historis Batu Nisan VOC di Batavia. Jakarta: Wedatama Widya Sastra.

Taylor, J. G. 2009. Kehidupan Sosial di Batavia: Orang Eropa dan Eurasia di Hindia Timur .Terjemahan oleh Tim Komunitas Bambu. Depok: Masup Jakarta. 